\title{
Bacterial Indole-3-Acetic Acid Influences Soil Nitrogen Acquisition in Barley and Chickpea
}

\author{
Shraddha Gang ${ }^{1, \dagger}$, Sheetal Sharma ${ }^{2, \dagger}$, Meenu Saraf ${ }^{2, *}$, Martin Buck ${ }^{1}$ and Jorg Schumacher ${ }^{1, *}$ \\ 1 Department of Life Science, Faculty of Natural Sciences, Imperial College, London SW7 2AZ, UK; \\ s.gang@imperial.ac.uk (S.G.); m.buck@imperial.ac.uk (M.B.) \\ 2 Department of Microbiology and Biotechnology, School of Sciences, Gujarat University, \\ Ahmedabad 380009, India; sheetumsharma2961994@gmail.com \\ * Correspondence: msaraf@gujaratuniversity.ac.in or sarafmeenu@gmail.com (M.S.); \\ j.schumacher@ic.ac.uk or j.schumacher@imperial.ac.uk (J.S.) \\ + These authors contributed equally to this work.
}

Citation: Gang, S.; Sharma, S.; Saraf, M.; Buck, M.; Schumacher, J. Bacterial Indole-3-Acetic Acid Influences Soil Nitrogen Acquisition in Barley and Chickpea. Plants 2021, 10, 780. https://doi.org/10.3390/ plants10040780

Academic Editor: Ivana Puglisi

Received: 1 February 2021

Accepted: 23 March 2021

Published: 16 April 2021

Publisher's Note: MDPI stays neutral with regard to jurisdictional claims in published maps and institutional affiliations.

Copyright: (c) 2021 by the authors. Licensee MDPI, Basel, Switzerland. This article is an open access article distributed under the terms and conditions of the Creative Commons Attribution (CC BY) license (https:// creativecommons.org/licenses/by/ $4.0 /)$.

\begin{abstract}
Farming of barley and chickpea is nitrogen $(\mathrm{N})$ fertilizer dependent. Using strategies that increase the nitrogen use efficiency (NUE) and its components, nitrogen uptake efficiency (NUpE) and nitrogen utilization efficiency (NUtE) would reduce the $\mathrm{N}$ fertilizer application in the soil and its adverse environmental effects. We evaluated the effects of three different strains of diazotroph Klebsiella (K.p. SSN1, K.q. SGM81, and K.o. M5a1) to understand the role of biological nitrogen fixation (BNF) and bacterial indole-3-acetic acid (IAA) on NUE of the plants. A field study revealed that K.p. SSN1 results in profound increment of root surface area by eightfold and threefold compared to uninoculated (control) in barley and chickpea, respectively. We measured significant increase in the plant tissue nitrogen, chlorophyll content, protein content, nitrate reductase activity, and nitrate concentration in the inoculated plants $(p \leq 0.05)$. Treated barley and chickpea exhibited higher NUE and the components compared to the control plants (K.p. SSN1 Z K.q. SGM81> K.o. M5a1). Specifically, K.q. SGM81 treatment in barley increased NUpE by 72\%, while in chickpea, K.p. SSN1 increased it by $187 \%$. The substantial improvement in the NUpE and NUE by the auxin producers K.p. SSN1 and K.q. SGM81 compared with non-auxin producer K.o. M5a1 was accompanied by an augmented root architecture suggesting larger contribution of IAA over marginal contribution of BNF in nitrogen acquisition from the soil.
\end{abstract}

Keywords: nitrogen use efficiency; nitrogen uptake efficiency; nitrogen utilization efficiency; Klebsiella; indole acetic acid; root architecture

\section{Introduction}

With rapid and continuing growth of the world's population and the resulting demand in food production, excessive use of chemical fertilizer is degrading the agricultural soil health. Amongst many others, lack of nitrogen is classified as an important abiotic stress factor [1] and its deficiency in soil negatively affects many physiological processes in a plant. To overcome this shortage, different forms of nitrogen are applied to the soil as nitrogen fertilizers. According to an FAO report, the worldwide consumption of nitrogen fertilizer in 2020 was 108.74 million tons, which is expected to reach 111.9 million tons in 2022 [2]. One alternative solution to replace or minimize the use of nitrogen fertilizers is to better harness the biological nitrogen fixation (BNF) in which nitrogenase enzymes from microorganisms can provide fixed nitrogen to plants [3]. However, the practice of using a microbial strategy to fix nitrogen is limited due to a lower output in terms of yield, hence the use of chemical nitrogen sources persists in agriculture [4]. One problem lies in the fact that only around $30 \%$ of the applied nitrogen is utilized by the crop plants and the remaining unutilized nitrogen causes severe environmental pollution [5]. Increased nitrogen use efficiency (NUE) could alleviate these environmental impacts and is generally 
divided into two phases; a. the nitrogen uptake efficiency (NUpE) of the plant that involves assimilation, and $\mathrm{b}$. nitrogen utilization efficiency (NUtE) that involves remobilization of nitrogen [6].

The use of plant growth promoting microorganisms (PGPMs) could be a feasible solution to improve NUE. The few main mechanisms of the rhizosphere that influence $\mathrm{N}$-uptake efficiency are: root size morphology, root $\mathrm{N}$ transporter system, and interaction of root-microorganisms such as plant growth-promoting bacteria (PGPB) [7]. Many PGPBs are reported to positively improve root system development by manipulating plant hormones such as auxins, cytokinins, or gibberellins [8,9], and hence the acquisition of some nutrients. $\mathrm{NO}_{3}{ }^{-}$and $\mathrm{NH}_{4}{ }^{+}$uptake systems may be enhanced by the interaction with arbuscular mycorrhizal fungi (AMF), PGPB, and some organic acids $[7,10]$. The pursuit of BNF, especially in cereals, started long ago with isolation of nitrogen-fixing bacteria from different cereal plants [11]. Few studies have also focused on the appearance of diazotrophs in association with cereal crops and evidence of nitrogen supply [12]. One such example of a bacterial diazotroph is Klebsiella. It has been dominant and widely pervasive in the rhizosphere of a variety of plants such as maize [13], wheat [14,15], and sugarcane [16]. Here we explore the potential of highly ubiquitous Klebsiella as a tool to improve plant NUE. We hypothesized two bacterial mechanisms that might play an important role. First, the nitrogen-fixing ability of the wild type strains, and second, the auxin (IAA) production. The latter will influence the root structure and thus help in acquisition of soil nitrogen (no chemical nitrogen fertilizer supplements in the present case). In proteobacteria, nitrogen fixation genes (nif) are generally transcribed by the alternative $\mathrm{s}^{54}$ RNA-polymerase under nitrogen limiting conditions and regulated by the enhancer binding protein NifA [17]. Auxin production depends on the expression of ipdC, coding for thiamindiphosphate-dependent indolepyruvate decarboxylase, which was reported to also be s ${ }^{54}$-dependent in the diazotrophic Azospirillum brasilense [18] and the non-diazotrophic Enterobacter cloacae [19].

To understand which out of the two aforementioned mechanisms has larger impact, the effects of three different strains of Klebsiella (from different origin) on a model monocot Hordeum vulgare (barley) and a dicot legume Cicer arietinum (chickpea) were analyzed. The selected wildtype strains were Klebsiella pneumoniae SSN1, Klebsiella quasipneumoniae SGM81, and Klebsiella oxytoca M5a1, which hereafter will be represented as K.p. SSN1, K.q. SGM81, and K.o. M5a1, respectively. The choice of strains was made considering their ability of BNF (K.p. SSN1, K.q. SGM81, and K.o. M5a1), IAA production (K.p. SSN1, K.q. SGM81), and a negative control $(\triangle n i f H)$ which is a nitrogenase minus variant of wild type K.o. M5a1 lacking both BNF and IAA production. Thus, we determined if: (1) wildtype Klebsiella strains (test strains) positively affect the barley and chickpea growth parameters, and (2) the enhanced structural context of root triggers the plant's NUE and its components.

\section{Results}

2.1. Characterization for Biological Nitrogen Fixation and Phytohormone Production in Klebsiella Strains

The strains K.q. SGM81, K.o. M5a1, and K.p. SSN1 were based on the prediction of BNF and IAA production activities from their whole genome sequence data (details described in Section 4). The presence of nif gene cluster and ipdC gene pathway in all three genomes indicate the BNF and IAA production activities in K.p. SSN1, K.q. SGM81, and K.o. M5a1 strains.

First, we screened all the Klebsiella strains (K.p. SSN1, K.q. SGM81, K.o. M5a1, M5a1 $\Delta$ nifH) for their nitrogenase activity and IAA production ability in batch culture. The results of acetylene reduction assay (ARA) showed that the wild type strains exhibit considerable nitrogenase activity, indicating the active expression of nifH gene. As shown in Figure 1, K.q. SGM81 showed maximum, i.e., $396.5 \mathrm{nmol}^{\mathrm{C}_{2} \mathrm{H}_{4} \mathrm{~h}^{-1} \mathrm{mg} \text { protein }}{ }^{-1}$ of nitrogenase activity, followed by K.p. SSN1 $\left(297.0 \mathrm{nmol} \mathrm{C}_{2} \mathrm{H}_{4} \mathrm{~h}^{-1} \mathrm{mg}_{\text {protein }}^{-1}\right)$. Nitrogenase activity of K.o. M5a1 was recorded as $293.5 \mathrm{nmol} \mathrm{C}_{2} \mathrm{H}_{4} \mathrm{~h}^{-1} \mathrm{mg}_{\text {protein }}{ }^{-1}$. As expected, no nitrogenase activity was detected in M5a1 $\Delta$ nifH. 


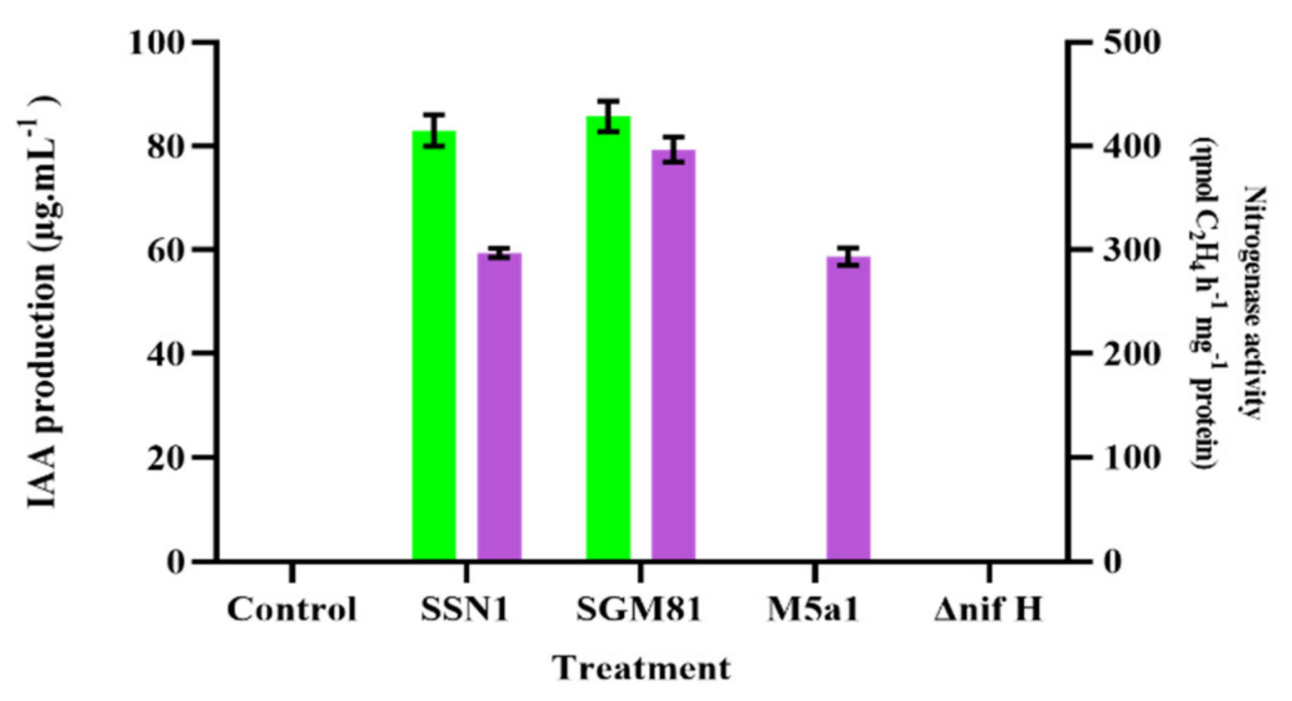

Nitrogenase

IAA

Figure 1. Indole-3-acetic acid (IAA) production and acetylene reduction in four strains. Control is the value of uninoculated media. Bars represents mean values of replicates. Error bars represent standard error from the mean $(n=5)$.

Next, we quantified the tryptophan-induced indole-3-acetic acid using the Salkowski method. The results of this assay are presented in Figure 1. The highest IAA production was seen in K.q. SGM81 $\left(85.75 \mu \mathrm{g} \mathrm{mL}^{-1}\right)$ followed by K.p. SSN1. K.o. M5a1 and its nifH mutant did not produce any IAA, suggesting a non-functional ipdC gene. A Clustal $\mathrm{O}$ multiple sequence alignment of ipdC sequences of the three strains (Figure S1) was carried out, showing pairwise percent identities $85.17 \%, 85.35 \%$, and $99.64 \%$ similarity in protein sequence between K.o. M5a1-K.q. SGM81, between K.o. M5a1-K.p. SSN1, and between K.q. SGM81-K.p. SSN1, respectively. However, the amino acid sequence alignment of ipdC of M5a1, SGM81, and SSN1 (Figure S1) shows 100\% identity of known highly conserved residues involved in $\mathrm{Mg}^{2+}$ binding (red) and thiamine pyrophosphate binding (blue highlighted) with the functional ipdC of Enterobacter cloacae, for which the structure and function has been detailed. Therefore, there is no obvious structure/function rational from the K.o. M5a1 ipdC coding sequence to explain the lack of K.o. M5a1 to produce IAA. Next, we inspected the promoter regions of K.q. SGM81 and K.o. M5a1. Recall that ipdC transcription was proposed to be ${ }^{54}$-dependent in Enterobacter cloacae and is $\mathrm{s}^{54}$-dependent diazotrophic Azospirillum brasilense [18]. We show that K.q. SGM81 has two near perfect s ${ }^{54}$ promoter sites at and around consensus the -24 and -12 sites from the transcriptional start with the required distance between them, whereas K.o. M5a1 shows no good s ${ }^{54}$ promoter sites (Figure S2). These finding suggest that the K.o. M5a1 ipdC s ${ }^{54}$ promoter is likely to have been corrupted. This seems feasible, given that K.o. M5a1 has been a decade-long laboratory strain.

\subsection{IAA Biosynthesis in Klebsiella Contributes to Enhanced Root Traits}

To understand the effect of diazotrophs on the root system of barley and chickpea, matured plants were harvested after 90 days (Figure S3) and roots were gently washed with water to remove adhered soil. Washed and drained-to-dry roots were then studied for six parameters, namely root length (RL), root fresh weight (RW), root dry weight (RDW), root diameter (Rootdia), root surface area (RSA), and the number of secondary roots (NSR). The results are described in Table 1. In general, the structural parameters of root in both plant types were positively altered by the wildtype strains. In barley, all the treated plants except $\Delta$ nifH showed superior phenotype than the control plants. Amongst all the traits, RSA and NSR were the most affected parameters. Compared to control, K.p. SSN1 showed profound 
effects on all the structural traits, specifically with eightfold and threefold increment in the RSA of barley and chickpea, respectively. The inoculation of chickpea with K.q. SGM81 resulted in maximum NSR increased by $113 \%$ and $60 \%$ than the control in barley and chickpea, respectively. The overall impact of different treatments in terms of their positive effect on barley and chickpea root can be summarized as K.p. SSN1 > K.q. SGM81 > K.o. M5a1 $>$ control $>\Delta n i f H$, as shown in Table 1. Compared to the non-inoculated, plants treated with the nifH mutant showed a decrease in the root traits. Since M5a1 $\Delta$ nifH has neither beneficial IAA production capacity nor fixes nitrogen, the most likely explanation is that the high titer of M5a1 $\Delta$ nifH may partly exclude other (e.g., IAA microbes) soilendogenous soil microbes in the rhizosphere from providing beneficial services to the plant. Plants under normal growth conditions establish a mutualistic relation with the soil flora, which could have been affected due to abundance of nifH mutant cells. Taken together, these results imply that Klebsiella strains capable of auxin production (K.p. SSN1 and K.q. SGM81) could largely be promoting enhanced root growth and hence more nutrient access compared to non-auxin producers (K.o. M5a1 and $\Delta$ nifH).

Table 1. Measurements of root morphology traits in barley and chickpea plants.

\begin{tabular}{|c|c|c|c|c|c|c|}
\hline Plants & Traits & & & Treatment & & \\
\hline \multirow{7}{*}{ Barley } & & Control & K.p. SSN1 & K.q. SGM81 & K.o. M5a1 & $\Delta$ nif $H$ \\
\hline & $\begin{array}{l}\text { Root Fresh } \\
\text { weight }(g)\end{array}$ & $1.5 \pm 0.039^{* * *}$ & $6.58 \pm 0.0084^{* * *}$ & $5.117 \pm 0.060^{* * *}$ & $1.84 \pm 0.0093^{* * *}$ & $1.205 \pm 0.085^{* * *}$ \\
\hline & $\begin{array}{c}\text { Root dry } \\
\text { weight }(\mathrm{g})\end{array}$ & $0.8 \pm 0.050^{* * *}$ & $4.217 \pm 0.1249^{* * *}$ & $3.4 \pm 0.057^{* *}$ & $0.9200 \pm \underset{* * *}{ \pm 0.01125}$ & $0.300 \pm 0.0057^{* * *}$ \\
\hline & $\begin{array}{l}\text { Root length } \\
(\mathrm{cm})\end{array}$ & $8.00 \pm 0.392^{* * *}$ & $22.12 \pm 0.1195^{* * *}$ & $18.08 \pm 0.149^{* * *}$ & $10.00 \pm 0.1493^{* * *}$ & $6.00 \pm 0.0077^{* * *}$ \\
\hline & $\begin{array}{l}\text { Root diameter } \\
(\mathrm{mm})\end{array}$ & $9.583 \pm 0.1417 *$ & $25.75 \pm .6180^{* * *}$ & $18.42 \pm 0.3780^{* * *}$ & $15.94 \pm 0.5707^{* * *}$ & $7.304 \pm 0.3696$ * \\
\hline & $\begin{array}{l}\text { Root surface } \\
\text { area }(\mathrm{cm})\end{array}$ & $220.7 \pm 16.02 * *$ & $1796 \pm 31.35^{* * *}$ & $1062.2 \pm 22.90^{* * *}$ & $494.5 \pm 29.47^{* * *}$ & $136.2 \pm 88.39 \mathrm{~ns}$ \\
\hline & $\begin{array}{l}\text { Number of } \\
\text { secondary } \\
\text { roots }\end{array}$ & $10.33 \pm 0.88^{* *}$ & $18.67 \pm 1.202^{* *}$ & $22.00 \pm 0.57^{* *}$ & $11.00 \pm 0.5774^{\mathrm{ns}}$ & $8.33 \pm 0.33^{\mathrm{ns}}$ \\
\hline \multirow{6}{*}{ Chickpea } & $\begin{array}{l}\text { Root Fresh } \\
\text { weight }(\mathrm{g})\end{array}$ & $1.117 \pm 0.060$ ** & $3.283 \pm 0.070^{* * *}$ & $2.5 \pm 0.03^{* *}$ & $1.735 \pm 0.04$ * & $0.89 \pm 0.008^{*}$ \\
\hline & $\begin{array}{c}\text { Root dry } \\
\text { weight }(\mathrm{g})\end{array}$ & $0.42 \pm 0.012 * *$ & $1.78 \pm 0.018^{* * *}$ & $1.43 \pm 0.0095^{* * *}$ & $0.52 \pm 0.0079^{* * *}$ & $0.266 \pm 0.006^{* * *}$ \\
\hline & $\begin{array}{l}\text { Root length } \\
(\mathrm{cm})\end{array}$ & $7.117 \pm 0.060 * * *$ & $19.82 \pm 0.1302^{* * *}$ & $18.68 \pm 0.364^{* * *}$ & $8.017 \pm 0.1108^{* *}$ & $7.033 \pm 0.066^{\mathrm{ns}}$ \\
\hline & $\begin{array}{l}\text { Root diameter } \\
(\mathrm{mm})\end{array}$ & $10.26 \pm 0.765$ * & $12.72 \pm 0.459^{\mathrm{ns}}$ & $11.18 \pm 0.415^{\mathrm{ns}}$ & $13.66 \pm 0.6018^{* *}$ & $12.74 \pm 0.4287$ * \\
\hline & $\begin{array}{l}\text { Root surface } \\
\text { area }(\mathrm{cm})\end{array}$ & $226.3 \pm 15.41^{* *}$ & $802.7 \pm 26.66^{* * *}$ & $676.2 \pm 13.93^{* * *}$ & $350.4 \pm 16.50^{* *}$ & $276.0 \pm 10.55^{\mathrm{ns}}$ \\
\hline & $\begin{array}{l}\text { Number of } \\
\text { secondary } \\
\text { roots }\end{array}$ & $3.33 \pm 0.88^{\mathrm{ns}}$ & $5.00 \pm 0.5^{\mathrm{ns}}$ & $5.33 \pm 0.3^{\mathrm{ns}}$ & $3.33 \pm 0.3^{\mathrm{ns}}$ & $4.00 \pm 0.57^{\mathrm{ns}}$ \\
\hline
\end{tabular}

Effect of five treatments on root architecture of barley and chickpea. Statistical analysis was done using GraphPad Prism 5 software calculated at $p \leq 0.05$. Data represents mean values of six replicates with standard error. Significance of data was analyzed using ANOVA and mentioned through ${ }^{* *}$. Key: ${ }^{*}(p \leq 0.05),{ }^{* *}(p \leq 0.01),{ }^{* * *}(p \leq 0.001),{ }^{\text {ns }}$ non-significant.

\subsection{Klebsiella Improves Shoot Phenotype and Biochemical Profiling}

To validate the positive effect of diazotrophs on aerial parts of the host plants, we assessed the effect of bioinoculation on structural and biochemical traits of the shoot system. 
Four structural traits, shoot fresh weight (SW), shoot dry weight (SDW), shoot length (SL), and grain weight (GW), were measured. Here, GW was a crucial parameter reflecting the yield of a crop. It was measured as grain weight $(\mathrm{g})$ per pod. The response was highly significant in K.p. SSN1 and K.q. SGM81 treatment in both plant varieties. Amongst all, K.p. SSN1 treatment showed the highest SL, SW, SDW, and GW, irrespective of monocot or dicot host plant (Figure 2). K.p. SSN1 resulted in 181.7\% and 198\% increase while K.q. SGM81 resulted in $174 \%$ and $155.2 \%$ increase in GW in barley and chickpea, respectively, over control plants. Compared to control plants, K.o. M5a1 resulted in 100\% higher barley GW and $57.6 \%$ higher chickpea GW. Effect of $\Delta$ nifH inoculation was non-significant on SDW of chickpea and on GW of both barley and chickpea.

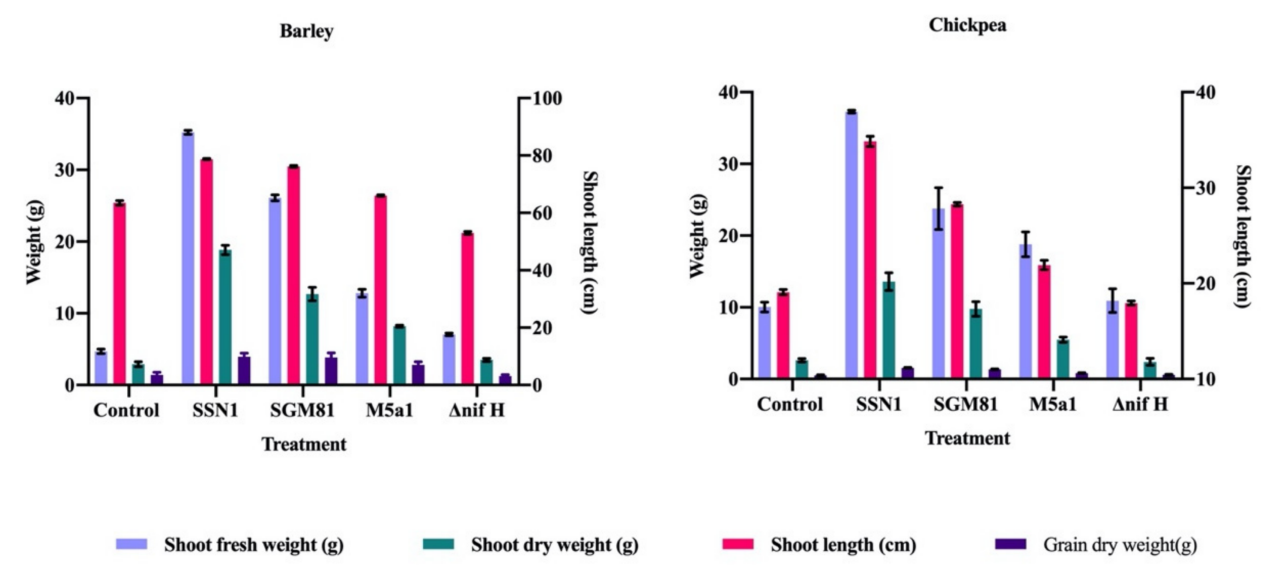

Figure 2. Effect of inoculation on barley and chickpea shoot traits from left to right. Shoot traits include shoot length, shoot fresh weight, shoot dry weight, and grain weight. Bars represent mean values of replicates. Error bars represent standard error from the mean $(n=6)$.

Next, we examined several biochemical characteristics of shoot, chlorophyll content $(\mathrm{Cl})$, protein content $(\mathrm{PR})$, nitrate reductase activity (NR), nitrate (NT) concentration, and total aboveground nitrogen (ABN). To study biochemical characteristics of plant postuprooting, it was washed and was air-dried or kept fresh as required. Table 2 represents the results of all biochemical traits. In comparison to control plants, content of all parameters was improved in plants treated with wild type Klebsiella strains. For Cl, K.p. SSN1 showed $41.7 \%$ and $106.2 \%$ higher content than control in barley and chickpea, respectively, also being the highest among all other treatments. Estimation of total PR revealed that in barley, the highest PR content was in K.p. SSN1-treated plants, whereas in chickpea, K.q. SGM81 resulted in the highest protein with 51\% increment compared to control. NR enzyme activity of K.p. SSN1 and K.q. SGM81-treated barley was almost similar. In chickpea, K.o. M5a1-treated plants resulted in $64.4 \%$ higher NR activity, which also was the highest among all other chickpea treatments. The highest NT was quantified in K.p. SSN1 plants of both varieties followed by K.q. SGM81 in barley and K.o. M5a1 in chickpea. Lastly, K.q. SGM81 resulted in the highest plant nitrogen in barley and K.p. SSN1 in chickpea, as shown in Table 2. The $\Delta$ nifH treatment failed to show any significant increase in the biochemical content above control plants. This demonstrates the failure of the $\Delta$ nifH Klebsiella in promoting plant growth. The improvement in all the biochemical traits in K.p. SSN1 and K.q. SGM81, but not K.o. M5a1, clearly demonstrates that a coupled effect of root growth-promoting traits (auxin production) and nitrogen-fixing ability of K.p. SSN1 and K.q. SGM81 is more vital than nitrogen-fixing ability alone of K.o. M5a1.

Collectively, from the above results, we infer that Klebsiella spp. contributed towards higher yield and improved biochemical characteristics, specifically those related to nitrogen accumulation or/and mobilization in barley and chickpea plants. 
Table 2. Measurements of biochemical traits in barley and chickpea plants.

\begin{tabular}{|c|c|c|c|c|c|c|}
\hline Plants & Traits & & & Treatment & & \\
\hline \multirow{6}{*}{ Barley } & & Control & K.p. SSN1 & K.q. SGM81 & K.o. M5a1 & $\Delta$ nif $H$ \\
\hline & $\begin{array}{l}\text { Chlorophyll } \\
\left(\mathrm{mg} \mathrm{mL}^{-1}\right)\end{array}$ & $1.079 \pm 0.0547$ * & $1.530 \pm 0.1281^{* *}$ & $1.372 \pm 0.110$ * & $1.362 \pm 0.0614$ * & $1.165 \pm 0.04829$ * \\
\hline & $\begin{array}{c}\text { Protein } \\
\left(\mathrm{mg} \mathrm{g}^{-1} \mathrm{FW}\right. \\
\left.\mathrm{h}^{-1}\right)\end{array}$ & $1.200 \pm 0.0774$ * & $2.130 \pm 0.1134^{* *}$ & $2.042 \pm 0.1428^{* *}$ & $1.395 \pm 0.1919^{* *}$ & $1.133 \pm 0.1436^{\mathrm{ns}}$ \\
\hline & $\begin{array}{c}\text { Nitrate } \\
\text { reductase } \\
\left(\mu \mathrm{g} \mathrm{g}^{-1} \mathrm{FW}\right. \\
\left.\mathrm{h}^{-1}\right)\end{array}$ & $10.22 \pm 0.3156^{* *}$ & $14.20 \pm 0.5447^{* * *}$ & $14.60 \pm 0.2781^{* * *}$ & $10.93 \pm 0.6344$ * & $10.12 \pm 0.4257$ * \\
\hline & $\begin{array}{l}\text { Nitrate } \\
\left(\mu g g^{-1}\right)\end{array}$ & $381.2 \pm 450.0^{* *}$ & $604.2 \pm 37.93^{* * *}$ & $593.5 \pm 33.25^{* * *}$ & $424.2 \pm 12.60^{\mathrm{ns}}$ & $395.1 \pm 22.26^{\mathrm{ns}}$ \\
\hline & $\begin{array}{l}\text { Total nitrogen } \\
\left(\mathrm{mg} \mathrm{g}^{-1}\right)\end{array}$ & $22.16 \pm 2.482 *$ & $34.81 \pm 3.875^{* *}$ & $38.16 \pm 1.447^{* *}$ & $29.66 \pm 4.425 *$ & $21.35 \pm 1.384^{\mathrm{ns}}$ \\
\hline \multirow{5}{*}{ Chickpea } & $\begin{array}{l}\text { Chlorophyll } \\
\left(\mathrm{mg} \mathrm{mL}^{-1}\right)\end{array}$ & $0.817 \pm \underset{* * *}{ \pm 0.07417}$ & $1.685 \pm 0045^{* *}$ & $1.450 \pm 0.065^{* *}$ & $1.222 \pm 0.1756^{* *}$ & $0.8275 \pm 0.060$ * \\
\hline & $\begin{array}{c}\text { Protein } \\
\left(\mathrm{mg} \mathrm{g}^{-1} \mathrm{FW}\right. \\
\left.\mathrm{h}^{-1}\right)\end{array}$ & $1.295 \pm 0.1350$ * & $1.760 \pm 0.1395$ * & $1.967 \pm 0.0928^{* *}$ & $1.577 \pm 0.0954^{\mathrm{ns}}$ & $1.433 \pm 0.0954^{\mathrm{ns}}$ \\
\hline & $\begin{array}{c}\text { Nitrate } \\
\text { reductase } \\
\left(\mu \mathrm{g} \mathrm{g}^{-1} \mathrm{FW}\right. \\
\left.\mathrm{h}^{-1}\right)\end{array}$ & $10.55 \pm 0.4796^{* *}$ & $15.53 \pm 1.322^{* * *}$ & $16.57 \pm 0.9735^{* * *}$ & $17.35 \pm 0.6020^{\mathrm{ns}}$ & $13.67 \pm 0.2257^{\mathrm{ns}}$ \\
\hline & $\begin{array}{l}\text { Nitrate } \\
\left(\mu g g^{-1}\right)\end{array}$ & $353.1 \pm 17.83^{* *}$ & $533.0 \pm 34.62 * *$ & $484.2 \pm 7.955^{* *}$ & $484.9 \pm 17.21^{\mathrm{ns}}$ & $397.3 \pm 6.1722^{\mathrm{ns}}$ \\
\hline & $\begin{array}{l}\text { Total nitrogen } \\
\quad\left(\mathrm{mg} \mathrm{g}^{-1}\right)\end{array}$ & $13.65 \pm 2.724^{* *}$ & $39.00 \pm 1.483^{* * *}$ & $33.00 \pm 3.183^{* * *}$ & $28.50 \pm 1.310^{* *}$ & $11.83 \pm 5.084^{\mathrm{ns}}$ \\
\hline
\end{tabular}

Effect of five treatments on biochemical traits of barley and chickpea. Statistical analysis was done using GraphPad Prism 5 software calculated at $p \leq 0.05$. Data represents mean values of six replicates with standard error. Significance of data was analyzed using ANOVA and mentioned through ${ }^{* *}$. Key: ${ }^{*}(p \leq 0.05),{ }^{* *}(p \leq 0.01),{ }^{* * *}(p \leq 0.001),{ }^{\text {ns }}$ non-significant.

\subsection{Klebsiella Demonstrates Effective Mobilization and Use of Nitrogen in Barley and Chickpea}

To evaluate the nitrogen mobilization ability of differently treated plants, NupE and NUtE were calculated. NUpE is the very first mechanism taking place when plant root comes in contact with the soil nitrogen. Once taken up, nitrogen is then transported to aerial parts of the plant via xylem and redistributed in the shoot system referring to NUtE. The total nitrogen quantification in the above section reflects the higher potential of K.p. SSN1 and K.q. SGM81 to yield better grain quality and improved NUE as compared to K.o. M5a1.

In general, as shown in Figure 3, NUE, NUpE, and NUtE in barley is significantly higher than that in chickpea. In barley, NUpE was the highest in K.q. SGM81 (72\% higher than control) whereas NUpE of chickpea was maximum (187\% higher than control) in K.p. SSN1 plants. The $\triangle$ nifH plants exhibited the lowest NUpE in both barley and chickpea. K.p. SSN1 treatment also showed maximum positive effect on NUtE and NUE of both barley and chickpea, followed by K.q. SGM81. The $\Delta$ nifH showed a little higher (28\%) NUtE in chickpea plants than control. Interestingly, K.o. M5a1, which was positive for BNF, consistently followed K.p. SSN1 and K.q. SGM81 in terms of its positive effect compared to control. The correlation plot between NUE and RSA is shown in Figure 4. It is evident that increase in NUE is congruent to the increase in RSA of the roots. 
(A)

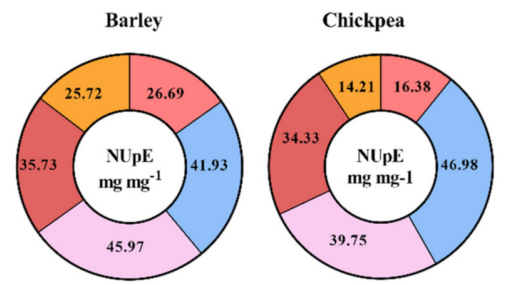

(B)
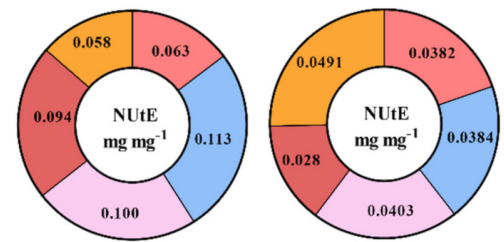

(C)

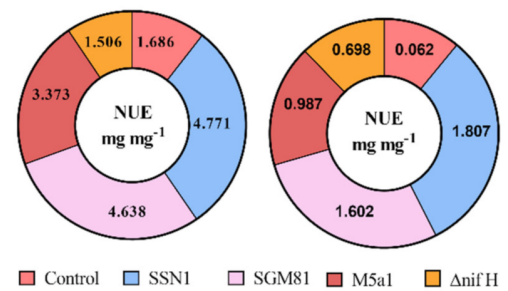

Figure 3. Nitrogen use efficiency and its components in barley and chickpea from left to right. (A) represents effect of inoculation on nitrogen uptake efficiency (NUpE), (B) represents effect of inoculation on nitrogen utilization efficiency (NUtE), (C) represents effect of inoculation on nitrogen use efficiency (NUE). Control is the value in uninoculated plants.
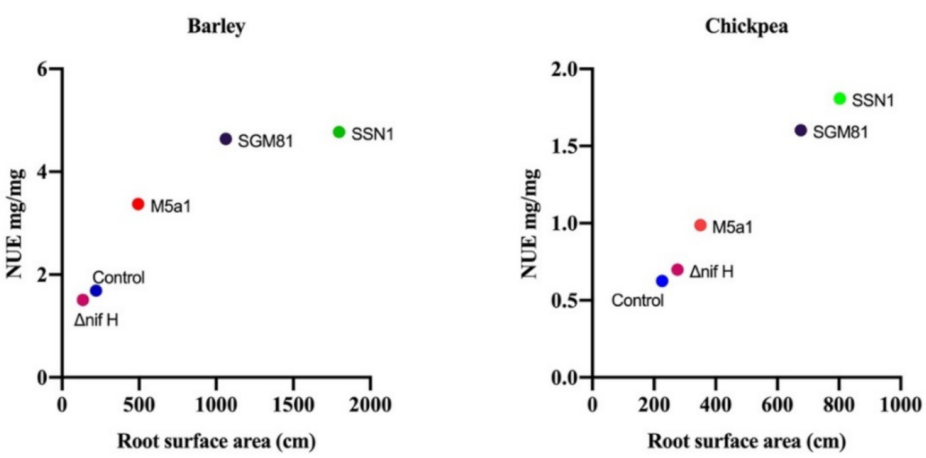

Figure 4. Correlation between root surface area (RSA) and nitrogen use efficiency (NUE) in barley and chickpea from left to right. The plot represents the increase in NUE with the increase in root surface area.

Both barley and chickpea had the similar influence of RSA on NUE, showing positive correlation between the two. This result suggests that stronger root establishment in the soil gives the plant an improved access to soil nitrogen.

\subsection{Principal Component Analysis}

A principal component analysis (PCA) biplot was carried out for all the traits studied. The association of traits among first and second principal component is shown in Figure 5. In barley (Figure 5A), principal component 1 (dimension 1 ) showed variation up to $82.2 \%$ comprising root structure parameters including RW, RL, and root diameter, all shoot morphological parameters, and biochemical traits, viz., $\mathrm{NR}, \mathrm{Cl}, \mathrm{PR}$, and $\mathrm{ABN}$ in presence of strains K.p. SSN1 and K.q. SGM81. RSA and NUtE lies on PC2 (dimension 2) showing negative correlation with $13.8 \%$ variation with other traits. Principal component analysis of chickpea is shown in Figure 5B, where both principal components explained about 90\% of the total variation. The principal component 1 (dimension 1) spanned all the traits but NUtE. RSA in chickpea, unlike barley, is loaded on PC1 showing positive correlation with 
NUE, NUpE, and all other traits (Table 3). The pattern of appearance of the control and four strains is similar in both barley and chickpea. Control (1) and $\Delta$ nifH (5) are close to one another on the far negative quadrant in PC2 (dimension 2), which indicates lack of any influence on the plant traits. K.o. M5a1 (4) falls apart from all the vectors on the negative quadrant, however, is still closer to the positive scale, indicating its intermediate effect being higher than control and $\Delta$ nifH and lower than other two wild type strains. K.p. SSN1 (2) and K.q. SGM81 (3) both are positively loaded in PC1 (dimension 1), reflecting maximum positive effect on all the studied parameters. From the spatial distribution of strains obtained here, it is inferred that majority traits are largely affected when plants are treated with K.p. SSN1 and K.q. SGM81 (Figure 5) and high correlation is established amongst all traits in presence of these strains (Table 3).

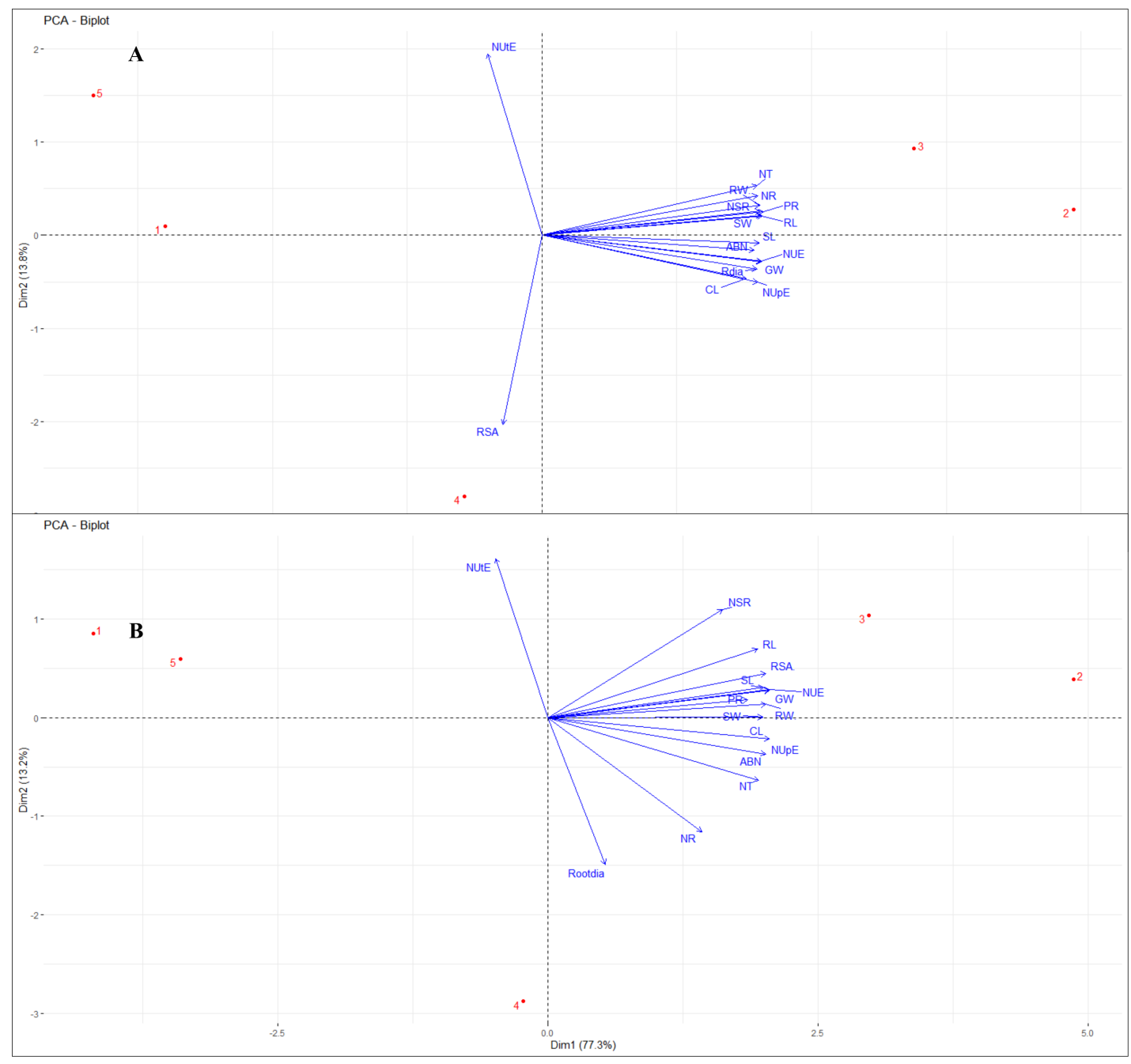

Figure 5. Principal component analysis (PCA) biplot for barley (A) and chickpea (B). Biplot represents correlation between plant traits with NUpE, NUtE, and NUE in different treatments. Red dots represent overall effect of all five treatments, viz., $1=$ control, $2=$ K.p. SSN1, $3=$ K.q. SGM81, $4=$ M5a1, and $5=\Delta$ nif H. Vectors in blue represent plant traits. NSR: number of secondary roots, RL: root length, RSA: root surface area, Rootdia: root diameter, SL: shoot length, SW: shoot fresh weight, RW: root fresh weight, GW: grain weight, PR: protein, $\mathrm{Cl}$ : chlorophyll, ABN: aboveground nitrogen, NR: nitrate reductase, NT: nitrate, NUtE: nitrogen utilization efficiency, NUpE: nitrogen uptake efficiency, NUE: nitrogen use efficiency. 
Table 3. Correlation of the plant traits (variables) of barley and chickpea with the principal components dimension 1 and dimension 2 .

\begin{tabular}{ccccc}
\hline Trait & \multicolumn{2}{c}{ Barley } & \multicolumn{2}{c}{ Chickpea } \\
\cline { 2 - 5 } & Dim.1 & Dim.2 & Dim.1 & Dim.2 \\
\hline Root fresh weight (RFW) & 0.9801 & -0.1458 & 0.9817 & 0.0430 \\
Root length (RL) & 0.9897 & -0.0874 & 0.9480 & 0.3087 \\
Shoot length (SL) & 0.9713 & 0.0506 & 0.9721 & 0.1266 \\
Total nitrogen (Nt) & 0.9438 & 0.0923 & 0.9705 & -0.2037 \\
Chlorophyll (Cl) & 0.9130 & 0.2394 & 0.9893 & -0.1326 \\
Nitrate reductase (NR) & 0.9650 & -0.1917 & 0.6626 & -0.5968 \\
Nitrate (NT) & 0.9664 & -0.2451 & 0.9306 & -0.3403 \\
Protein (PR) & 0.9918 & -0.1094 & 0.8870 & 0.0474 \\
Number of secondary roots (NSR) & 0.9806 & -0.1137 & 0.7895 & 0.4932 \\
Nitrogen use efficiency (NUE) & 0.9776 & 0.1497 & 0.9938 & 0.1065 \\
Nitrogen uptake efficiency (NUpE) & 0.9632 & 0.2575 & 0.9705 & -0.2037 \\
Nitrogen utilization efficiency (NUtE) & -0.2301 & -0.9407 & -0.2182 & 0.7675 \\
Grain weight (GW) & 0.9774 & 0.1509 & 0.9945 & 0.1042 \\
Root diameter (Rdia) & 0.9629 & 0.1877 & 0.2290 & -0.7412 \\
Root surface area (RSA) & -0.1874 & 0.9773 & 0.9815 & 0.1875 \\
Root dry weight (RDW) & 0.9760 & -0.1830 & 0.9616 & 0.2426 \\
Shoot dry weight (SDW) & 0.9821 & 0.0292 & 0.9883 & 0.0800 \\
\hline
\end{tabular}

\section{Discussion}

We explored the potential of diazotrophic Klebsiella strains in plant nutrient $(\mathrm{N})$ uptake and its utilization acting as both biofertilizer and phytostimulator. The results indicate that using Klebsiella strains as bioinoculants in barley and chickpea fields improves the plant growth, biochemical traits, and NUE. All the wild type Klebsiella strains showed considerable nitrogenase activity (Figure 1). This shows that Klebsiella inoculants can be proficiently used as biofertilizer.

K.p. SSN1 and K.q. SGM81 were found to produce substantial amounts of IAA (57.50 $\mu \mathrm{g} \mathrm{mL}^{-1}$ and $85.75 \mu \mathrm{g} \mathrm{mL}^{-1}$ IAA, respectively) using tryptophan as substrate indicating active expression of $i p d C$ pathway for IAA production. On the contrary, despite the presence of gene ipdC, K.o. M5a1 showed no detectable IAA production. The protein sequence of K.o. M5a1 ipdC gene showed no obvious sequence deviation from K.q. SGM81 and K.p. SSN1 (including cofactor binding sites, see Supplementary Information S1). The few most common examples of previously reported Klebsiella are Klebsiella pneumoniae producing $22.7 \mathrm{mg} \mathrm{L}^{-1}$ of IAA [20] and Klebsiella pnb8 producing as high as $869 \mu \mathrm{g} \mathrm{mL}^{-1}$, using plant extract as substrate [21]. IAA is crucial for root development in plants, and IAA-producing microorganisms benefit root architecture in different ways. At phenotypic level, IAA is involved in increasing root hair, promoting adventitious root initiation, bursting out root hair, etc. [22], while at cellular level, in plant cell division, extension, and differentiation, specially of the vascular system of plants $[23,24]$, and hence, enhanced nutrient acquisition [25]. In the present experiments, root phenotype of barley and chickpea was positively affected upon the inoculation of K.q. SGM81 and K.p. SSN1 above K.o. M5a1, favoring over all plant growth and development. This reinforces the potential involvement of IAA in promoting structural morphological changes in the root architecture of K.q. SGM81- and K.p. SSN1-inoculated plants, and that K.o. M5a1 does not contribute to this mechanism in a way that would otherwise be observed due to plant hormone auxin. We were able to relate our findings with some other studies conducted in different crops. Dhungana and Itoh [26] reported Klebsiella sp. Sal 1 for increasing fresh root weight in tomato and radish, K. pneumoniae demonstrated increase in root length of inoculated moth beans and wheat [20], and K. variicola AY-13 for inducing adventitious root initiation in soy bean seedling [27]. These results, along with our observations in barley and chickpea, show the profound role of Klebsiella in root development. 
PGPB can modify the physiology and functioning of plant parts other than root [22]. Two mechanisms are thought to be accountable for this; first is well documented where plant roots under the influence of PGPB result in enhanced nutrient availability [22]. This will be taken up by aerial parts of the plant leading to modification in the primary metabolism which subsequently results in growth. Second, PGPB by some unknown signal triggers the systemic responses which might lead to plant growth [22]. Due to the former, general phenomenon of nutrient acquisition takes place including nitrogen, phosphorus, and other macro- and micronutrients. Nitrogen availability regulates the $\mathrm{C}$ and $\mathrm{N}$ in the plant due to the allocation of resources between roots and shoots [28]. In the present study, all the wild type strains improved the overall shoot development compared to control, especially K.p. SSN1 (Figure 2). These results are in agreement with Zhu et al. [29], who reported enhanced shoot length and biomass in wheat upon inoculation with PGPR. Experiments conducted by [30] on chickpea in sandy soil resulted into enhanced shoot fresh weight and dry weight in treated plants.

The biochemical parameters $(\mathrm{Cl}, \mathrm{PR}$, and $\mathrm{NT})$ that contribute to plant nitrogen were enhanced. The abundance of these biochemical traits in K.p. SSN1 and K.q. SGM81 above K.o. M5a1 clearly demonstrates that coupled effect of root growth-promoting traits (auxin production) and nitrogen-fixing ability of K.p. SSN1 and K.q. SGM81 on total plant nitrogen is more vital than nitrogen-fixing ability alone of K.o. M5a1. This is justifiable on the basis of "multiple mechanism theory" given by Bashan and Levanony [31], which assumes that more than one factor may be responsible for plant growth. Few studies conducted recently emphasize mechanisms other than BNF for improving overall plant nitrogen. For example, Calvo et al. [32] studied different non-nitrogen-fixing Bacillus strains which were able to upregulate nitrate and ammonium uptake genes in Arabidopsis. Nitrate was being absorbed by the plasma membrane of the cortical and epidermal cells of the roots, thus bringing root structural elements to the frontline [33]. After absorbing and assimilating $\mathrm{NO}^{-}{ }_{3}$ in the root in some proportion, the remainder was being reduced to ammonium $\left(\mathrm{NH}^{+}{ }_{4}\right)$ by nitrate reductase (NR) and transported upwards through the xylem for assimilation in the shoot [34]. Thus, the nitrate reductase present in the plant is proportional to the nitrate and evidence of the high or low plant nitrogen content. As shown in Table 2, the result of nitrate reductase assay in barley experiments synchronize with the aforementioned relationship increasing proportionately with increase in plant nitrate.

Improvement in NUE of a plant results in increase of growth yield and decrease in the environmental nitrogen pollution, as suggested by Perchlik and Tegeder [35]. In our study, NUE and its components were increased in both barley and chickpea (Figure 3) upon treatment with wild type strains of Klebsiella. We attribute the increase in NUpE to the access of soil nitrogen and hence to the well-developed root system, as hypothesized by Win et al. [36]. This is largely supported by our results of root development in K.p. SSN1 and K.q. SGM81 plants. Plant growth is associated with nutrient uptake and its proper distribution in the aerial part. Ideally, a plant is considered healthy when, post uptake, it uses the acquired nitrogen dexterously. This depends on genetic construct of a plant and its internal $\mathrm{N}$ requirement for metabolism [37]. The NUtE of the treated plants increase compared to control does not show any close correlation with NUE and NUpE (Figure 5). Nitrogen use efficiency not only depends on an efficient $\mathrm{N}$ uptake from the soil, but also on the internal transport, storage, recycling, remobilization, and growth stage of the plants [38,39]. Hence, both NUpE and NUtE play important roles in regulating the overall NUE of a plant. Worku et al. [40] showed that in tropical maize hybrids, NUE was influenced by both NUpE and NUtE. However, Rotundo et al. [41], working on soybean, reported that $\mathrm{NUpE}$ is more critical than NUtE in determining the increase in NUE. Our results from PCA biplot (Figure 5A,B) clearly indicate that NUpE is closely associated with NUE, and thus is more influential than NUtE in NUE management of both the model plants when treated with diazotroph Klebsiella. 


\section{Materials and Methods}

\subsection{Bacteria and Culture Conditions}

Three wildtype diazotroph Klebsiella strains (K.p. SSN1, K.q. SGM81, and K.o. M5a1) isolated from different rhizosphere soil samples were used as test strains. K.q. SGM81 and K.p. SSN1 were isolated from the rhizosphere soil of Dianthus caryophyllus (carnation) and barley, respectively, from Gujarat, India. The soil source of isolation of K.o. M5a1 strain is unknown, however, for current study, it was obtained from Buck Lab at the Department of Life Sciences, Imperial College, London. The whole genome sequence of K.o. M5a1 and K.p. SSN1 strains were determined, and the bio project was deposited at DDBJ/ENA/GenBank under PRJNA649683 and PRJNA643013, respectively. The details of K.q. SGM81 sequence (PRJEB21197) are mentioned in our previous manuscript [9]. K.q. SGM81, K.p. SSN1, and K.o. M5a1 were identified as Klebsiella quasipneumoniae, Klebsiella pneuomoniae, and Klebsiella oxytoca, respectively, based on the average nucleotide identity (ANI)-based taxonomy. A nifH mutant of K.o. M5a1, a nitrogenase minus variant, was used as a negative control. All the strains were grown in nutrient broth (HiMedia, Ahmedabad, India), unless specifically stated. K.p. SSN1 and K.q. SGM81 strains were used in the study for their ability to produce plant hormone auxin (IAA) and nitrogenase production. K.o. M5a1 was taken as a positive control solely for nitrogenase production, and negative for all other PGPR attributes including IAA. $\Delta$ nifH was nitrogenase minus strain, and hence a negative control for both IAA and nitrogenase production under nitrogen fixing conditions where it does not grow. These strains were maintained at $4{ }^{\circ} \mathrm{C}$ as agar slants until experimental use.

\subsection{Recombineering M5a1 $\Delta$ nifH}

The $\Delta$ nifH knockout mutant was derived by Lambda Red recombineering as described by Datsenko and Wanner [42]. Oligonucleotides were designed in order to amplify a curable kanamycin resistance cassette, flanked by Flippase Recognition Targets, (FRTnptII-FRT) from the pGEM-T-KanFRT plasmid [43] with $60 \mathrm{nt}$ overhangs homologous to the flanking regions of the Ko M5a1 nifH region (pGEM-T-KanFRT binding region in upper case): nifH_mutF, tctgctggcaaacactcaacaacaggagaagtcaccatgaccatgcgtcaatgcgctattGTGTAGGCTGGAGCTGCTTC; nifH_mutR, tggatcagcgccagattacgttcgccegttgcgttggtcatcataattgtcctgtgctcatccTCCTTAGTTCCTATTCCG. PCR was performed using Phusion polymerase (Thermo Scientific) with $25 \mathrm{ng}$ template plasmid and an annealing temperature of $55^{\circ} \mathrm{C}$. Template DNA was removed by DpnI digestion prior to gel extraction of products. M5a1 was transformed with the pKD46 plasmid, expressing the Lambda Red genes required for homologous recombination under the control of an arabinose-inducible promoter. Competent Red-recombinase expressing cells were prepared in super optimal broth $(\mathrm{SOB})(0.5 \%(w / v)$ yeast extract, $2 \%(w / v)$ tryptone, $10 \mathrm{mM} \mathrm{NaCl}, 2.5 \mathrm{mM} \mathrm{KCl}$, $20 \mathrm{mM} \mathrm{MgSO}_{4}$ ), to which L-arabinose was added to a final concentration of $10 \mathrm{mM}$ once $\mathrm{OD}_{600}$ reached 0.1. Cells were grown to an $\mathrm{OD}_{600}$ of $0.4-0.6$ before being washed three times in sterile cold $10 \%$ glycerol solution. Approximately $1 \mu \mathrm{g}$ of purified PCR product was incubated with $100 \mu \mathrm{L}$ of competent cells on ice for $30 \mathrm{~min}$ prior to electroporation. Transformed cells were recovered at $30^{\circ} \mathrm{C}$ for $3 \mathrm{~h}$ before being plated out on $\mathrm{LB}$ agar plates supplemented with kanamycin. Kanamycin-resistant colonies were used to generate seed cultures from which genomic DNA was extracted. Locus-specific homologous recombination was confirmed by diagnostic PCR, combining primers specific to regions flanking the knockout locus with those specific to the nptII cassette, and Sanger sequencing.

\subsection{Acetylene Reduction Assay}

ARA was carried out to determine the BNF of the isolates following the method described by Kaushal and Kaushal [44]. Briefly, a nitrogen-free Jensen liquid medium was used to inoculate the cultures and was allowed to grow till mid exponential phase at $30^{\circ} \mathrm{C}$ for $48 \mathrm{~h}$ at $100 \mathrm{rpm}$. Aliquots with optical density of 0.1 at $600 \mathrm{~nm}$ were prepared and used as inoculum for nitrogen-free medium in the air-free assay vials and again incubated till exponential phase was reached. The headspace of the vial was replaced with acetylene 
$(10 \% v / v)$ and incubated for $18 \mathrm{~h}$. After incubation, the gas sample was injected in a Brucker 450 gas chromatograph with flame ionization detector. Calibration was done using standard ethylene gas. Nitrogenase activity was determined in terms of ethylene produced. After ARA, cells were pre-digested, and protein concentration was calculated using Bradford reagent [45]. The nitrogenase activity was calculated using the formula:

Nitrogenase activity $\left(\right.$ nmole $\left.\mathrm{C}_{2} \mathrm{H}_{4} \mathrm{~h}^{-1} \mathrm{mg}_{\text {protein }}{ }^{-1}\right)=\mathrm{C} \times \mathrm{P}_{\mathrm{s}} \times \mathrm{V} / \mathrm{P}_{\text {std }} \times \mathrm{T} \times \mathrm{P}$

where:

$\mathrm{C}=$ concentration of ethylene in $\eta$ moles.

$\mathrm{P}=$ protein concentration of bacterial cell in $\mathrm{mg}$.

$\mathrm{P}_{\mathrm{S}}=$ peak height of sample.

$\mathrm{V}=$ volume of air space in the assay vial.

$\mathrm{P}_{\text {Std }}=$ peak height of standard.

$\mathrm{T}=$ time of incubation in $\mathrm{h}$.

\subsection{IAA Extraction and Determination by Salkowski Reagent Method}

IAA production and estimation was carried out following the method given by Gang et al. [46]. IAA biosynthesis in the cultures was induced by supplementing nutrient broth with $0.1 \%(w / v)$ L-tryptophan, and cultures were incubated in the dark at $30^{\circ} \mathrm{C}$ on an orbital shaker at $200 \mathrm{rpm}$. IAA production and secretion were measured in culture supernatants after $24 \mathrm{~h}$ using Salkowski reagent. Briefly, $1 \mathrm{~mL}$ of culture supernatant was mixed with $1 \mathrm{~mL}$ of Salkowski reagent and incubated in the dark for $30 \mathrm{~min}$. Development of pink color was spectrophotometrically measured at $536 \mathrm{~nm}$ and IAA quantified using an IAA standard.

\subsection{Field Experimental Design}

\subsubsection{Site Description}

To understand and evaluate the effect of three different Klebsiella strains on the model crop plants barley and chickpea, a full-length seasonal study was conducted in field for respective crops. A site $\left(23.0658^{\circ} \mathrm{N}, 72.5138^{\circ} \mathrm{E}\right)$ located at Sola Road, Ahmedabad, India, was selected for the field experiments. Both barley and chickpea were sown in the month of November 2019 and harvested in February 2020. The physical characteristics of the soil were recorded as: $\mathrm{pH} 6.8$, organic matter $0.97 \%$, sand $32.2 \%$, silt $35.3 \%$, and clay $29.5 \%$. The nitrogen content of the site before our plantation was $0.83 \mathrm{mg} \mathrm{N} \mathrm{g}^{-1}$ soil as estimated at Indian Farmers Fertilizer Cooperative Limited (IFFCO). The classification of this soil type is aridisols, according to United States Department of Agriculture (USDA) soil taxonomic system [47].

\subsubsection{Plant Treatment and Growth}

Certified barley seeds (Karan 201, from Bashino agro India pvt Ltd.), and chickpea seeds (black chickpea, from Gujarat Junagadh gram 3) were purchased. A total of $10 \mathrm{~g}$ of seeds (barley and chickpea) for every strain and a control were weighed and sterilized. For sterilizing, the seeds were washed with $70 \%$ ethanol for $1 \mathrm{~min}$ and subsequently rinsed with $20 \%$ sodium hypochlorite thrice, followed by a final wash with sterile distilled water [48]. The sterile seeds were then immersed for $15 \mathrm{~min}$ in $0.5 \%(w / v)$ carboxymethyl cellulose $(\mathrm{CMC})$ solution prepared in sterile distilled water to increase the adhesion of bacterial cells on seed surface. The coated seeds were subjected to the bacterization. To prepare the culture for seed bacterization, all strains were inoculated in the sterile nitrogen-free liquid Jensen medium and allowed to grow overnight. After reaching the desired growth at $\mathrm{OD}_{600} 0.5$, cells were pelleted out, washed, and resuspended in $100 \mathrm{~mL}$ of $0.6 \%(w / v) \mathrm{NaCl}$ so as to remove the traces of nutrient medium. Seeds were soaked in the final prepared culture suspension for $30 \mathrm{~min}$, allowing proper adhesion of the bacterial cells all over the seed surface. For control, seeds were soaked in sterile $0.6 \% \mathrm{NaCl}$. Randomized complete 
block design was used in the field with a split plot arrangement for different treatments. Each sub-plot consisted of prepared seeds for respective treatment. Single seeds were sown at the depth of approximately $1 \mathrm{~cm}$, maintaining the distance of around $15 \mathrm{~cm}$ between two neighboring seeds and $25 \mathrm{~cm}$ row-to-row spacing. After 15 days of sowing, a booster dose was given to each row. All strains were grown in sterile $1 \mathrm{~L}$ nitrogen-free Jensen liquid medium to achieve $\mathrm{OD}_{600}$ of 0.5 . For booster dose, cells were pelleted to discard any nutrient medium followed by washing and resuspension of the cell pellet in $0.6 \%(w / v)$ $\mathrm{NaCl}$ of final volume $1 \mathrm{~L}$. The control set was just supplemented with the same volume of $0.6 \% \mathrm{NaCl}$. A complete stepwise description of the process is shown as image schema (Figure S4).

\subsection{Plant Growth Parameters}

Plant traits were studied, with six replicates randomly chosen. The traits were categorized into three sections:

1. Root morphology traits comprising RL, RW, RDW, and NSR. These root traits were measured after uprooting the treated and control plants at the harvest stage after 90 days. Pictures of the roots were taken and processed in Image J for estimating the root diameter. In addition, RSA was calculated using the formula RSA $=$ root length $\times$ root diameter $\times \Pi$.

2. Shoot morphology traits comprising of SL, SW, SDW, and GW per plant.

3. Biochemical traits:

\subsubsection{Chlorophyll Content}

$\mathrm{Cl}$ content was determined following the method given by Arnon [49]. Briefly, 0.5 $\mathrm{g}$ fresh leaf was homogenized in $5 \mathrm{~mL}$ of $80 \%$ acetone and centrifuged at 10,000 rpm for $5 \mathrm{~min}$. The collected supernatant was subjected to optical density measurement at 663 and $645 \mathrm{~nm}$ wavelength. Total chlorophyll was calculated as:

$$
\mathrm{Cl}\left(\mathrm{mg} \mathrm{mL}^{-1}\right)=\mathrm{Cl} \mathrm{a}+\mathrm{Cl} \mathrm{b} \text {. }
$$

where

$\mathrm{Cl} \mathrm{a}\left(\mathrm{mg} \mathrm{mL}^{-1}\right)=12.7$ A663-2.69 A645.

$\mathrm{Cl} \mathrm{b}\left(\mathrm{mg} \mathrm{mL}^{-1}\right)=22.9 \mathrm{~A} 645-4.68 \mathrm{~A} 663$.

A645 = absorbance at a wavelength of $645 \mathrm{~nm}$.

A663 = absorbance at a wavelength of $663 \mathrm{~nm}$.

\subsubsection{Total Protein}

Determination of total soluble PR was done according to Bradford method [50], using albumin bovine. About $0.5 \mathrm{~g}$ plant shoot sample was crushed and homogenized in $5 \mathrm{~mL}$ phosphate buffer. The homogenized mixture was boiled at $100{ }^{\circ} \mathrm{C}$ in water bath for $10 \mathrm{~min}$ and centrifuged at $3000 \mathrm{rpm}$ for $5 \mathrm{~min}$. The final reaction consisted of $2 \mathrm{~mL} \mathrm{~d} \mathrm{H}_{2} \mathrm{O}$, centrifuged extract $(20 \mu \mathrm{L})$, and Bradford reagent $(0.5 \mathrm{~mL})$. Finally, the optical density was recorded at $595 \mathrm{~nm}$ wavelength using a spectrophotometer.

\subsubsection{Plant Nitrogen Concentration}

The total aboveground nitrogen $(\mathrm{ABN})$ at maturity was measured by Kjeldahl technique, as described by AppliChem [51]. The plants after uprooting were washed thoroughly to get rid of any soil particles. Plant samples were then air-dried for seven days to determine dry weight. The perfectly dried and ground plant was placed in a Kjeldahl digestion flask. To the plant sample, $1 \mathrm{~g}$ of catalyst and $5 \mathrm{~mL}$ of concentrated $\mathrm{H}_{2} \mathrm{SO}_{4}$ were added. The flask was subjected to heating for $2 \mathrm{~h}$ for digestion of the sample and cooled at room temperature. A total of $30 \mathrm{~mL}$ of distilled water with four drops of phenolphthalein reagent was added to the flask. $\mathrm{N}$ was collected via distillation in $4 \%(w / v)$ boric acid solution. A 
blank was run without any plant tissue sample. Total $\% \mathrm{~N}$ was determined by titrating the obtained solution with $0.1 \mathrm{M} \mathrm{HCl}$, and expressed as $\mathrm{mg} \mathrm{N} \mathrm{g}^{-1}$ of dry matter.

\subsubsection{Nitrate and Nitrate Reductase Activity}

A detailed technique for plant nitrate estimation, as described by Zhao and Wang [52], was followed using fresh plant samples. Briefly, fresh plant samples were air-dried in the dark, and aqueous solution was prepared using $1 \mathrm{~mL}$ deionized water, centrifuged and supernatant collected. To $0.1 \mathrm{~mL}$ of the supernatant, $0.4 \mathrm{~mL}$ salicylic acid-sulfuric acid mixture was added and allowed to rest for $20 \mathrm{~min}$ at room temperature. A total of $9.5 \mathrm{~mL}$ of $8 \% \mathrm{NaOH}$ was added to the above mixture and allowed to cool for $30 \mathrm{~min}$. The final mixture was read at $\mathrm{OD}_{410}$. NT concentration was calculated by applying the formula $\mathrm{C}=140.86 \times \mathrm{OD}_{410}-1.1831$. Using the value of $\mathrm{C}$, final plant nitrate content was calculated as $\mathrm{Y}=\mathrm{CV} / \mathrm{W}$, where $\mathrm{Y}$ is nitrate content $\left(\mu \mathrm{g} \mathrm{g}^{-1}\right), \mathrm{C}$ is nitrate concentration, $\mathrm{V}$ is total volume of extracted sample $(\mathrm{mL})$, and $\mathrm{W}$ is weight of sample $(\mathrm{g})$.

For NR activity, $200 \mathrm{mg}$ of fresh plant sample was taken in a vial containing chilled $8 \mathrm{~mL}$ of $100 \mathrm{mM}$ phosphate buffer, $0.2 \mathrm{~mL}$ of $50 \mathrm{mM} \mathrm{KNO}_{3}$, and $1 \%(v / v)$ isopropanol as described by Silveira et al. [53]. The vial was subjected to vacuum infiltration and incubated for $30 \mathrm{~min}$ at $30{ }^{\circ} \mathrm{C}$. Vials were then placed in a water bath for $5 \mathrm{~min}$ to cease the enzymatic activity. The released nitrite was determined by colorimetric reaction with 1:1 ratio of sulfanilamide prepared in $1 \mathrm{~mL}$ of $1 \mathrm{M} \mathrm{HCl}$ and $0.02 \% \mathrm{~N}$-napthyl-ethylene diamine. OD was recorded at $540 \mathrm{~nm}$.

\subsection{Nitrogen Use Efficiency and Its Components}

Upon measuring the plant nitrogen, the following indexes were calculated using the formula given by Moll et al. [54]:

NUpE: $A B N / N s$.

NUtE: $G w / A B N$.

NUE: Gw/Ns.

Where: $\mathrm{ABN}$ is total aboveground nitrogen, $N s$ is available soil nitrogen $\left(0.83 \mathrm{mg} \mathrm{g}^{-1}\right.$ soil), and $G w$ is grain weight.

\subsection{Statistical Analysis}

A two-way ANOVA and descriptive analysis were performed to analyze the effect of BNF and IAA by strains on nitrogen use efficiency of the barley and chickpea using GraphPad Prism 8.0. Level of significance was studied for mean comparison at $5 \%$ significance level. The data is represented as mean \pm standard error (SE) of six replicates. PCA was performed in R (3.6) using strains as individuals and traits as variables. The contribution of each measured and calculated trait towards total variability was established by PCA. The correlation of each variable and individual with the principal components was also generated to understand their contribution.

\section{Conclusions}

Being a highly nutritious and staple food of large populations, barley and chickpea are among the world's most grown crops, and hence the contributors to food nitrogen footprint. The field experiments demonstrate the effectivity of the three tested diazotrophs klebsiella quasipneumoniae SGM81, Klebsiella pneumoniae SSN1, and Klebsiella oxytoca M5a1 in significantly increasing the nitrogen uptake and use efficiencies and overall improvement in morphology and biochemical parameters of both the crops, however still maintaining the order K.p. SSN1 $\geq$ K.q. SGM81 > K.o. M5a1. This order difference could be attributed to expression of a single plant beneficial trait (BNF) in K.o. M5a1, yet more than one (IAA and BNF) in K.p. SSN1 and K.q. SGM81. The enhanced ability for nitrogen utilization in plants could perhaps be facilitated by using molecular biotechnology tools to improve genes of the plant system. We further conclude that K.p. SSN1 is a strong candidate for bioinoculation for barley and chickpea in agriculture. For application on a wide variety of 
crops and vegetables, the effects of other plant growth-promoting attributes of K.p. SSN1 and K.q. SGM81, such as phosphate solubilization, siderophore production, etc., could be explored and scaled from in vitro to field trials.

Supplementary Materials: The following are available online at https://www.mdpi.com/article/ 10.3390/plants10040780/s1, Figure S1: Multiple sequence alignment, Figure S2: Promoters of ipdC in SGM81 and M5a1, Figure S3: Plant morphology of barley and chickpea, Figure S4: Schematic representation of plant experimental set up.

Author Contributions: Conceptualization, S.G. and S.S.; methodology, S.S.; software, S.S.; validation, S.G. and J.S.; formal analysis, S.G.; investigation, S.G. and S.S.; resources, S.G. and S.S.; data curation, S.S.; writing—original draft preparation, S.G.; writing—review and editing, M.S., J.S., and M.B.; supervision, M.S. and J.S.; project administration, M.B. and M.S. All authors have read and agreed to the published version of the manuscript.

Funding: This research was supported by grants from the UK-India Education and Research Initiative (UKIERI) project 2018-20. The research at Imperial College, London, was funded by British council (Grant no. P72898). Funding to Gujarat University was availed from Department of Science and Technology (Grant no. DST/INT/UK/P-156/2017).

Data Availability Statement: The datasets generated and analyzed during the current study are available in the DDBJ/ENA/GenBank under the following accession numbers: K.o. M5a1-PRJNA649683 ( https://www.ncbi.nlm.nih.gov/bioproject/?term=PRJNA649683, accessed on 1 February 2021) K.p. SSN1-PRJNA643013 (https:/ / www.ncbi.nlm.nih.gov/bioproject/?term=PRJNA643013, accessed on 1 February 2021) K.q. SGM81-PRJEB21197 (https:/ /www.ncbi.nlm.nih.gov/bioproject/?term=PRJEB2 1197, accessed on 1 February 2021).

Acknowledgments: The authors are grateful to Ruth Schmitz, Streit Lab, Germany for providing with Klebsiella oxytoca M5a1 strain to Martin Buck's lab. We are thankful to India farmers fertilizers cooperative limited (IFFCO), Ahmedabad, India, for support with soil analysis. We thank Naman Mangukia from Bioinnovations, Mumbai, India for his contribution to data submission at NCBI.

Conflicts of Interest: The authors declare no conflict of interest.

\section{References}

1. Hartman, K.; Tringe, S.G. Interactions between Plants and Soil Shaping the Root Microbiome under Abiotic Stress. Biochem. J. 2019, 476, 2705-2724. [CrossRef]

2. FAO. Food and Agriculture Organization of the United Nations World Fertilizer Trends and Outlook to 2022; FAO: Rome, Italy, 2019.

3. Andrews, M.; Lea, P. Our Nitrogen 'Footprint': The Need for Increased Crop Nitrogen Use Efficiency. Ann. Appl. Biol. 2013, 163, 165-169. [CrossRef]

4. He, H.; Yang, R.; Li, Y.; Ma, A.; Cao, L.; Wu, X.; Chen, B.; Tian, H.; Gao, Y. Genotypic Variation in Nitrogen Utilization Efficiency of Oilseed Rape (Brassica Napus) under Contrasting N Supply in Pot and Field Experiments. Front. Plant Sci. 2017, 8, 1825. [CrossRef] [PubMed]

5. Hakeem, K.R.; Mir, B.A.; Qureshi, M.I.; Ahmad, A.; Iqbal, M. Physiological Studies and Proteomic Analysis for Differentially Expressed Proteins and Their Possible Role in the Root of N-Efficient Rice (Oryza Sativa L.). Mol. Breed. 2013, 32, 785-798. [CrossRef]

6. Kant, S.; Bi, Y.-M.; Rothstein, S.J. Understanding Plant Response to Nitrogen Limitation for the Improvement of Crop Nitrogen Use Efficiency. J. Exp. Bot. 2011, 62, 1499-1509. [CrossRef] [PubMed]

7. Di Benedetto, N.A.; Corbo, M.R.; Campaniello, D.; Cataldi, M.P.; Bevilacqua, A.; Sinigaglia, M.; Flagella, Z. The Role of Plant Growth Promoting Bacteria in Improving Nitrogen Use Efficiency for Sustainable Crop Production: A Focus on Wheat. AIMS Microbiol. 2017, 3, 413. [CrossRef]

8. Moubayidin, L.; Di Mambro, R.; Sabatini, S. Cytokinin-Auxin Crosstalk. Trends Plant Sci. 2009, 14, 557-562. [CrossRef]

9. Gang, S.; Saraf, M.; Waite, C.J.; Buck, M.; Schumacher, J. Mutualism between Klebsiella SGM 81 and Dianthus Caryophyllus in Modulating Root Plasticity and Rhizospheric Bacterial Density. Plant Soil 2017. [CrossRef]

10. Hawkins, H.-J.; George, E. Reduced15N-Nitrogen Transport through Arbuscular Mycorrhizal Hyphae to Triticum Aestivum L. Supplied with Ammonium vs. Nitrate Nutrition. Ann. Bot. 2001, 87, 303-311. [CrossRef]

11. Rosenblueth, M.; Ormeño-Orrillo, E.; López-López, A.; Rogel, M.A.; Reyes-Hernández, B.J.; Martínez-Romero, J.C.; Reddy, P.M.; Martínez-Romero, E. Nitrogen Fixation in Cereals. Front. Microbiol. 2018, 9, 1794. [CrossRef]

12. Van Deynze, A.; Zamora, P.; Delaux, P.-M.; Heitmann, C.; Jayaraman, D.; Rajasekar, S.; Graham, D.; Maeda, J.; Gibson, D.; Schwartz, K.D. Nitrogen Fixation in a Landrace of Maize Is Supported by a Mucilage-Associated Diazotrophic Microbiota. PLoS Biol. 2018, 16, e2006352. [CrossRef] 
13. Kifle, M.H.; Laing, M.D. Isolation and Screening of Bacteria for Their Diazotrophic Potential and Their Influence on Growth Promotion of Maize Seedlings in Greenhouses. Front. Plant Sci. 2016, 6, 1225. [CrossRef] [PubMed]

14. Cakmakci, M.L.; Evans, H.; Seidler, R. Characteristics of Nitrogen-FixingKlebsiella Oxytoca Isolated from Wheat Roots. Plant Soil 1981, 61, 53-63. [CrossRef]

15. Iniguez, A.L.; Dong, Y.; Triplett, E.W. Nitrogen Fixation in Wheat Provided by Klebsiella Pneumoniae 342. Mol. Plant-Microbe Interact. 2004, 17, 1078-1085. [CrossRef] [PubMed]

16. Lin, L.; Li, Z.; Hu, C.; Zhang, X.; Chang, S.; Yang, L.; Li, Y.; An, Q. Plant Growth-Promoting Nitrogen-Fixing Enterobacteria Are in Association with Sugarcane Plants Growing in Guangxi, China. Microbes Environ. 2009, 27, 391-398. [CrossRef]

17. Dixon, R.; Kahn, D. Genetic Regulation of Biological Nitrogen Fixation. Nat. Rev. Microbiol. 2004, 2, 621. [CrossRef] [PubMed]

18. Lambrecht, M.; Vande Broek, A.; Dosselaere, F.; Vanderleyden, J. The IpdC Promoter Auxin-responsive Element of Azospirillum Brasilense, a Prokaryotic Ancestral Form of the Plant AuxRE? Mol. Microbiol. 1999, 32, 889-891. [CrossRef] [PubMed]

19. Coulson, T.J.; Patten, C.L. The TyrR Transcription Factor Regulates the Divergent Akr-IpdC Operons of Enterobacter Cloacae UW5. PLoS ONE 2015, 10, e0121241. [CrossRef]

20. Sachdev, D.P.; Chaudhari, H.G.; Kasture, V.M.; Dhavale, D.D.; Chopade, B.A. Isolation and Characterization of Indole Acetic Acid (IAA) Producing Klebsiella Pneumoniae Strains from Rhizosphere of Wheat (Triticum Aestivum) and Their Effect on Plant Growth. Indian J. Exp. Biol. 2009, 47, 993-1000.

21. Jasim, B.; Jimtha, C.J.; Jyothis, M.; Radhakrishnan, E. Plant Growth Promoting Potential of Endophytic Bacteria Isolated from Piper Nigrum. Plant Growth Regul. 2013, 71, 1-11. [CrossRef]

22. Vacheron, J.; Desbrosses, G.; Bouffaud, M.-L.; Touraine, B.; Moënne-Loccoz, Y.; Muller, D.; Legendre, L.; Wisniewski-Dyé, F.; Prigent-Combaret, C. Plant Growth-Promoting Rhizobacteria and Root System Functioning. Front. Plant Sci. 2013, 4, 356. [CrossRef] [PubMed]

23. Spaepen, S.; Vanderleyden, J.; Remans, R. Indole-3-Acetic Acid in Microbial and Microorganism-Plant Signaling. FEMS Microbiol. Rev. 2007, 31, 425-448. [CrossRef] [PubMed]

24. Duca, D.; Lorv, J.; Patten, C.L.; Rose, D.; Glick, B.R. Indole-3-Acetic Acid in Plant-Microbe Interactions. Antonie van Leeuwenhoek 2014, 106, 85-125. [CrossRef]

25. Li, X.; Zeng, R.; Liao, H. Improving Crop Nutrient Efficiency through Root Architecture Modifications. J. Integr. Plant Biol. 2016, 58, 193-202. [CrossRef]

26. Dhungana, S.A.; Itoh, K. Effects of Co-Inoculation of Indole-3-Acetic Acid-Producing and-Degrading Bacterial Endophytes on Plant Growth. Horticulturae 2019, 5, 17. [CrossRef]

27. Kim, M.; Oh, H.-S.; Park, S.-C.; Chun, J. Towards a Taxonomic Coherence between Average Nucleotide Identity and 16S RRNA Gene Sequence Similarity for Species Demarcation of Prokaryotes. Int. J. Syst. Evol. Microbiol. 2014, 64, 346-351. [CrossRef] [PubMed]

28. Walch-Liu, P.; Filleur, S.; Gan, Y.; Forde, B.G. Signaling Mechanisms Integrating Root and Shoot Responses to Changes in the Nitrogen Supply. Photosynth. Res. 2005, 83, 239-250. [CrossRef]

29. Zhu, Y.; Wang, Z.; Wang, J.; Wang, Z.; Zhou, J. Plant Growth-Promoting Rhizobacteria Improve Shoot Morphology and Photosynthesis in Dryland Spring Wheat. Biomed. Eng. Environ. Eng. 2014, 145, 343-350.

30. Khan, N.; Bano, A.M.; Babar, A. Impacts of Plant Growth Promoters and Plant Growth Regulators on Rainfed Agriculture. PLoS ONE 2020, 15, e0231426. [CrossRef]

31. Bashan, Y.; Levanony, H. Current Status of Azospirillum Inoculation Technology: Azospirillum as a Challenge for Agriculture. Can. J. Microbiol. 1990, 36, 591-608. [CrossRef]

32. Calvo, P.; Zebelo, S.; McNear, D.; Kloepper, J.; Fadamiro, H. Plant Growth-Promoting Rhizobacteria Induce Changes in Arabidopsis Thaliana Gene Expression of Nitrate and Ammonium Uptake Genes. J. Plant Interact. 2019, 14, 224-231. [CrossRef]

33. Forde, B.G. Nitrate Transporters in Plants: Structure, Function and Regulation. Biochim. Biophys. Acta BBA-Biomembr. 2000, 1465, 219-235. [CrossRef]

34. Raghuveer Rao, P.; Neeraja, C.; Vishnukiran, T.; Srikanth, B.; Vijayalakshmi, P.; Subhakara Rao, I.; Swamy, K.; Kondamudi, R.; Sailaja, N.; Subrahmanyam, D. Nitrogen Use Efficiency Ciency in Irrigated Rice for Climate Change-A Case Study; Directorate of Rice Research: Hyderabad, India, 2014.

35. Perchlik, M.; Tegeder, M. Improving Plant Nitrogen Use Efficiency through Alteration of Amino Acid Transport Processes. Plant Physiol. 2017, 175, 235-247. [CrossRef]

36. Win, K.T.; Okazaki, K.; Ookawa, T.; Yokoyama, T.; Ohwaki, Y. Influence of Rice-Husk Biochar and Bacillus Pumilus Strain TUAT-1 on Yield, Biomass Production, and Nutrient Uptake in Two Forage Rice Genotypes. PLoS ONE 2019, 14, e0220236. [CrossRef]

37. Ladha, J.; Pathak, H.J.; Krupnik, T.; Six, J.; van Kessel, C. Efficiency of Fertilizer Nitrogen in Cereal Production: Retrospects and Prospects. Adv Agron. 2005, 87, 85-156.

38. Akter, Z.; Lupwayi, N.Z.; Balasubramanian, P. Nitrogen Use Efficiency of Irrigated Dry Bean (Phaseolus Vulgaris L.) Genotypes in Southern Alberta. Can. J. Plant Sci. 2017, 97, 610-619. [CrossRef]

39. Hossain, M.A.; Kamiya, T.; Burritt, D.; Tran, L.-S.P.; Fujiwara, T. Plant Macronutrient Use Efficiency: Molecular and Genomic Perspectives in Crop Plants; Academic Press: Cambridge, MA, USA, 2017; ISBN 0-12-811294-8.

40. Worku, M.; Bänziger, M.; Erley, G.S.A.; Friesen, D.; Diallo, A.O.; Horst, W.J. Nitrogen Uptake and Utilization in Contrasting Nitrogen Efficient Tropical Maize Hybrids. Crop Sci. 2007, 47, 519-528. [CrossRef] 
41. Rotundo, J.L.; Borrás, L.; De Bruin, J.; Pedersen, P. Soybean Nitrogen Uptake and Utilization in Argentina and United States Cultivars. Crop Sci. 2014, 54, 1153-1165. [CrossRef]

42. Datsenko, K.A.; Wanner, B.L. One-Step Inactivation of Chromosomal Genes in Escherichia Coli K-12 Using PCR Products. Proc. Natl. Acad. Sci. USA 2000, 97, 6640-6645. [CrossRef] [PubMed]

43. Zumaquero, A.; Macho, A.P.; Rufián, J.S.; Beuzón, C.R. Analysis of the Role of the Type III Effector Inventory of Pseudomonas Syringae Pv. Phaseolicola 1448a in Interaction with the Plant. J. Bacteriol. 2010, 192, 4474-4488. [CrossRef] [PubMed]

44. Kaushal, M.; Kaushal, R. Acetylene Reductase Activity and Molecular Characterization of Plant Growth Promoting Rhizobacteria to Know Efficacy in Integrated Nutrient Management System. Indian J. Biotechnol. 2015, 14, 221-227.

45. He, F. Bradford Protein Assay. Bio-Protocol 2011, 101, e45. [CrossRef]

46. Gang, S.; Sharma, S.; Saraf, M.; Buck, M.; Schumacher, J. Analysis of Indole-3-Acetic Acid (IAA) Production in Klebsiella by LC-MS/MS and the Salkowski Method. Bio-Protocol 2019, 9, e3230. [CrossRef]

47. Staff, S. Keys to Soil Taxonomy, 12th ed.; USDA-Natural Resources Conservation Service: Washington, DC, USA, 2014.

48. Bent, A. Arabidopsis Thaliana Floral Dip Transformation Method. Agrobacterium Protoc. 2006, 87-104.

49. Arnon, D.I. Copper Enzymes in Isolated Chloroplasts. Polyphenoloxidase in Beta Vulgaris. Plant Physiol. 1949, 24, 1-15. [CrossRef]

50. Bradford, M.M. A Rapid and Sensitive Method for the Quantitation of Microgram Quantities of Protein Utilizing the Principle of Protein-Dye Binding. Anal. Biochem. 1976, 72, 248-254. [CrossRef]

51. AppliChem, P. Nitrogen Determination by Kjeldahl Method; PanReac AppliChem: Darmstadt, Germany, 2017.

52. Zhao, L.; Wang, Y. Nitrate Assay for Plant Tissues. Biochem. Biophys. Res. Commun. 2017, 7, e2029. [CrossRef]

53. Silveira, J.; Matos, J.; Cecatto, V.; Viegas, R.; Oliveira, J. Nitrate Reductase Activity, Distribution, and Response to Nitrate in Two Contrasting Phaseolus Species Inoculated with Rhizobium Spp. Environ. Exp. Bot. 2001, 46, 37-46. [CrossRef]

54. Moll, R.; Kamprath, E.; Jackson, W. Analysis and Interpretation of Factors Which Contribute to Efficiency of Nitrogen Utilization 1. Agron. J. 1982, 74, 562-564. [CrossRef] 